\title{
Inventory Management Models with Variable Holding Cost and Salvage value
}

\author{
R.Mohan ${ }^{1}$, R.Venkateswarlu ${ }^{2}$ \\ I'Mathematics Dept, College of Military Engineering- Pune, India) \\ ${ }^{2}$ (GITAM School of International Business -GITAM University, Visakhapatnam, India)
}

\begin{abstract}
Inventory management models are developed for deteriorating items when the demand rate is assumed to be linear function of time and the deterioration rate is proportional to time. The model is solved when shortages are allowed. The salvage value is used for deteriorated items in the system. A numerical example is taken to discuss the sensitivity of the models.
\end{abstract}

Key words: Deterioration rate, linear demand, salvage value, shortages, Time-dependent models,

\section{Introduction}

The assumption of constant demand rate is not always applicable to many inventory items like electronic goods, vegetables, food stuffs, fashionable clothes etc., since fluctuations in demand rate. Introducing new products will attract more in demand during the growth phase of their life cycle. It is evident that, some product may decline due to the introduction of new products due to the preference or influencing customer's choice. So it is worth attempt the phenomenon to develop deteriorating inventory models with time-varying demand rate pattern. In developing Inventory models two kinds of time-varying demands so far (i) Continuous time \& (ii) discrete time. Many continuous -time inventory models have been developed taking in to the consideration like linearly increasing /decreasing demand [i.e., $D(t)=a+b t[a \geq 0, b>0$ or $b<0]$. Ghare and Schrader (1963) studied an inventory model for exponentially decaying. Covert and Philip (1973) developed an inventory model for time dependent rate of deterioration. Aggarwal (1978) proposed an order level inventory model for a system with constant rate of deterioration. Dave and Patel (1981) studied a lot size model for time proportional demand with constant deterioration. Deb and Choudhuri (1987) studied a heuristic approach for replenishment of trended inventories with shortages. Hariga (1995) developed an inventory model of deteriorating items for time-varying demand with shortages. Chakraborti and Choudhuri (1996) proposed an EOQ model for deteriorating items of linear trend in demand with shortages in all cycles. Giri and Chaudhuri (1997) developed a heuristic model for deteriorating items of time varying demand and costs considering shortages. Goyal and Giri (2001) studied survey of recent trend in deteriorating inventory model. Mondal et. al (2003) developed an inventory model of ameliorating items for price dependent demand rate. You (2005) studied the inventory system for the products with price and time dependent demands.

Ajanta Roy (2008) proposed an inventory model for deteriorating items with price dependent demand and time varying holding cost with and without shortages. Mishra and Singh (2010) studied an inventory model for deteriorating items with time dependent demand and partial backlogging. Recently, Mishra (2012) developed an inventory model with Weibull rate of deterioration and constant demand. He incorporated variable holding cost considering shortages and also salvage value. Vikas Sharma and Rekha (2013) developed an inventory model for time dependant demand for deteriorating items with Weibull rate of deterioration and shortages.

In this paper, we consider an order level inventory problem with time-dependent deterioration when the demand rate is a linear function of time. Shortages are allowed in this case and the time horizon is infinite. The optimal total cost is obtained considering the salvage value for deteriorated items. The sensitivity analysis is done with numerical example.

\section{Assumptions and notations}

The mathematical model is developed on the following assumptions and notations:

(i) The demand rate $D(t)$ at time $t$ is assumed to be $D(t)=a+b t, a \geq 0, \boldsymbol{b} \neq \mathbf{0}$, .

(ii) Replenishment rate is infinite and lead time is zero.

(iii) $\mathrm{A}$, the ordering cost per order is known and constant.

(iv) $\theta(t)=\theta t$ is the deterioration rate, $0<\theta<1$.

(v) $\quad \mathrm{C}$, the cost per unit

(vi) $\mathrm{h}+\alpha \mathrm{t}, \mathrm{h}>0, \alpha>0$, the holding cost per unit

(vii) $I(t)$ is the inventory level at time $t$.

(viii) The order quantity in one cycle is q. 
(ix) The salvage value $\gamma^{*} \mathrm{C}, 0 \leq \gamma<1$ is associated with deteriorated units during a cycle time.

(x) $\quad \mathrm{D}$, The number of deteriorating units per order with one cycle time.

(xi) $\pi$ is the shortage cost per unit per order

\section{Formulation and solution of the model}

The differential equation which describes the instantaneous inventory level at time $t$ can be written as

$\frac{d I_{1}(t)}{d t}+\theta t I(t)=-(a+b t), 0 \leq t \leq t_{1}$

$\frac{d I_{2}(t)}{d t}=-(a+b t), \quad t_{1} \leq t \leq T$

with the initial condition $I_{1}(t)=I_{2}(t)=0$, at $t=t_{1}$

The solution of equation (1) using initial conditions is given by

$$
\begin{aligned}
& I_{1}(t)=-\left\{\left(a t+b \frac{t^{2}}{2}\right)+\theta\left(a \frac{t^{3}}{6}+b \frac{t^{4}}{8}\right)+\theta^{2}\left(a \frac{t^{5}}{40}+b \frac{t^{6}}{48}\right)\right\} e^{-\theta \frac{t^{2}}{2}} \\
& +\mathrm{K} e^{-\theta \frac{t^{2}}{2}} \\
& =-\left\{\left(a t+b \frac{t^{2}}{2}\right)+\theta\left(a \frac{t^{3}}{6}+b \frac{t^{4}}{8}\right)+\theta^{2}\left(a \frac{t^{5}}{40}+b \frac{t^{6}}{48}\right)\right\}\left(1-\theta \frac{t^{2}}{2}+\theta^{2} \frac{t^{4}}{8}\right) \\
& +K\left(1-\theta \frac{t^{2}}{2}+\theta^{2} \frac{t^{4}}{8}\right)
\end{aligned}
$$

Using the condition $I_{1}\left(t_{1}\right)=0$, we get the value of K. Now substituting this value in the above equation, the solution is obtained as

$$
\begin{aligned}
& I_{1}(t)=\left\{a\left(t_{1}-t\right)+\frac{b\left(t_{1}{ }^{2}-t^{2}\right)}{2}\right\}+\theta\left\{\frac{a\left(t_{1}{ }^{3}-t^{3}\right)}{6}+\frac{b\left(t_{1}{ }^{4}-t^{4}\right.}{8}\right\}+ \\
& \theta^{2}\left\{\frac{a\left(t_{1}{ }^{5}-t^{5}\right)}{40}+\frac{b\left(t_{1}{ }^{6}-t^{6}\right)}{48}\right\}-\theta\left(\frac{a\left(t^{2} t_{1}-t^{3}\right)}{2}+\frac{b\left(t^{2} t_{1}{ }^{2}-t^{4}\right)}{4}\right) \\
& -\theta^{2}\left(\frac{a}{12}\left(t_{1}{ }^{3} t^{2}-t^{5}\right)+\frac{b}{16}\left(t_{1}{ }^{4} t^{2}-t^{6}\right)\right) \\
& +\theta^{2}\left(\frac{a}{8}\left(t^{4} t_{1}-t^{5}\right)+\frac{b}{16}\left(t_{1}{ }^{2} t^{4}-t^{6}\right)\right)
\end{aligned}
$$

Using $I_{1}(0)=Q$, we obtain

$Q=\left[a t_{1}+\frac{b t_{1}^{2}}{2}+\theta\left(\frac{a t_{1}^{3}}{6}+\frac{b t_{1}^{4}}{8}\right)+\theta^{2}\left(\frac{a t_{1}^{5}}{40}+\frac{b t_{1}^{6}}{48}\right)\right]$

The solution of equation (2) using the boundary condition $I_{2}\left(t_{1}\right)=0$ is

$$
I_{2}(t)=a\left(t_{1}-t\right)+\frac{b}{2}\left(t_{1}^{2}-t^{2}\right)
$$

\section{Inventory Model with shortages}

The total cost of the inventory system consists of the following cost:

1. $\quad$ Carrying cost $/$ holding cost per cycle $=\int_{0}^{t_{1}}(h+\alpha t) I(t) d t$ 


$$
\begin{aligned}
I H C= & h\left[\frac{a t_{1}^{2}}{2}+\frac{b t_{1}^{3}}{3}+\theta\left(\frac{a t_{1}^{4}}{12}+\frac{2 b t_{1}^{5}}{3}\right)+\theta^{2}\left(0.0111 a t_{1}^{6}+0.00952 b t_{1}^{7}\right)\right] \\
& +\alpha\left[\frac{a t_{1}^{3}}{6}+\frac{b t_{1}^{4}}{8}+\theta\left(\frac{a t_{1}^{5}}{4}+\frac{b t_{1}^{6}}{40}\right)+\theta^{2}\left(\frac{a t_{1}^{7}}{336}+\frac{b t_{1}^{8}}{384}\right)\right]
\end{aligned}
$$

2. $\quad$ Ordering cost $(\mathrm{OC})=\mathrm{A}$

3. The number of units that deteriorated during this cycle time is

$$
\begin{gathered}
D=Q-\int_{0}^{t_{1}} D(t) d t, \text { where } D(t)=(a+b t), \\
D=\left[\theta\left(\frac{a t_{1}^{3}}{6}+\frac{b t_{1}^{4}}{8}\right)+\theta^{2}\left(\frac{a t_{1}^{5}}{40}+\frac{b t_{1}^{6}}{48}\right)\right]
\end{gathered}
$$

4. Cost due to deterioration $=\mathrm{C} * \mathrm{D}$

$$
C D=C\left[\theta\left(\frac{a t_{1}^{3}}{6}+\frac{b t_{1}^{4}}{8}\right)+\theta^{2}\left(\frac{a t_{1}^{5}}{40}+\frac{b t_{1}^{6}}{48}\right)\right]
$$

5. Shortage cost (SC) $=\pi \int_{0}^{t_{1}} I_{2}(t) d t$

$$
S C=\pi\left[a\left(\frac{T^{2}}{2}-t_{1} T\right)+\frac{b}{2}\left(\frac{T^{3}}{3}+\frac{2 t_{1}^{3}}{3}-t_{1}^{2} T\right)+\frac{a t_{1}^{2}}{2}\right]
$$

6. Salvage Value (SV) of deteriorated units $=\gamma * C D$

$$
S V=\gamma C\left[\theta\left(\frac{a t_{1}^{3}}{6}+\frac{b t_{1}^{4}}{8}\right)+\theta^{2}\left(\frac{a t_{1}^{5}}{40}+\frac{b t_{1}^{6}}{48}\right)\right]
$$

Total Cost $\left(T C\left(t_{1}, T\right)\right)=$ Inventory Holding cost + Ordering cost + + Shortage cost + Cost due to deterioration - Salvage value.

$$
T C\left(t_{1}, T\right)=\frac{1}{T}\left[\begin{array}{l}
h\left[\frac{a t_{1}^{2}}{2}+\frac{b t_{1}^{3}}{3}+\theta\left(\frac{a t_{1}^{4}}{12}+\frac{2 b t_{1}^{5}}{3}\right)+\theta^{2}\left(0.0111 a t_{1}^{6}+0.00952 b t_{1}^{7}\right)\right] \\
+\alpha\left[\frac{a t_{1}^{3}}{6}+\frac{b t_{1}^{4}}{8}+\theta\left(\frac{a t_{1}^{5}}{4}+\frac{b t_{1}^{6}}{40}\right)+\theta^{2}\left(\frac{a t_{1}^{7}}{336}+\frac{b t_{1}^{8}}{384}\right)\right]+A \\
\pi\left[a\left(\frac{T^{2}}{2}-t_{1} T\right)+\frac{b}{2}\left(\frac{T^{3}}{3}+\frac{2 t_{1}^{3}}{3}-t_{1}^{2} T\right)+\frac{a t_{1}^{2}}{2}\right] \\
+C(1-\gamma)\left[\theta\left(\frac{a t_{1}^{3}}{6}+\frac{b t_{1}^{4}}{8}\right)+\theta^{2}\left(\frac{a t_{1}^{5}}{40}+\frac{b t_{1}^{6}}{48}\right)\right]
\end{array}\right]
$$

The necessary condition for minimizing the total cost is

$$
\frac{\partial\left(T C\left(t_{1}, T\right)\right)}{\partial t_{1}}=0 \quad \text { and } \quad \frac{\partial\left(T C\left(t_{1}, T\right)\right)}{\partial T}=0, \text { i,e. }
$$




$$
\begin{aligned}
& \frac{\partial\left(T C\left(t_{1}, T\right)\right)}{\partial t_{1}}=\frac{1}{T}\left[\begin{array}{l}
h\left[a t_{1}+b t_{1}^{2}+\theta\left(\frac{a t_{1}^{3}}{3}+\frac{10 b t_{1}^{4}}{3}\right)+\theta^{2}\left(0.0111 * 6 a t_{1}^{5}+0.00952 * 7 b t_{1}^{6}\right)\right] \\
+\alpha\left[\frac{a t_{1}^{2}}{2}+\frac{b t_{1}^{3}}{2}+\theta\left(\frac{5 a t_{1}^{4}}{4}+\frac{6 b t_{1}^{5}}{40}\right)+\theta^{2}\left(\frac{7 a t_{1}^{6}}{336}+\frac{8 b t_{1}^{7}}{384}\right)\right]+ \\
\pi\left[a(-T)+b\left(t_{1}^{2}-t_{1} T\right)+a t_{1}\right] \\
+C(1-\gamma)\left[\theta\left(\frac{a t_{1}^{2}}{2}+\frac{b t_{1}^{3}}{2}\right)+\theta^{2}\left(\frac{a t_{1}^{4}}{8}+\frac{b t_{1}^{5}}{8}\right)\right]
\end{array}\right]=0 \\
& \frac{\partial\left(T C\left(t_{1}, T\right)\right)}{\partial T}=-\frac{1}{T^{2}}\left[\begin{array}{l}
h\left[\frac{a t_{1}^{2}}{2}+\frac{b t_{1}^{3}}{3}+\theta\left(\frac{a t_{1}^{4}}{12}+\frac{2 b t_{1}^{5}}{3}\right)+\theta^{2}\left(0.0111 a t_{1}^{6}+0.00952 b t_{1}^{7}\right)\right] \\
+\alpha\left[\frac{a t_{1}^{3}}{6}+\frac{b t_{1}^{4}}{8}+\theta\left(\frac{a t_{1}^{5}}{4}+\frac{b t_{1}^{6}}{40}\right)+\theta^{2}\left(\frac{a t_{1}^{7}}{336}+\frac{b t_{1}^{8}}{384}\right)\right]+A \\
\pi\left[a\left(\frac{T^{2}}{2}-t_{1} T\right)+\frac{b}{2}\left(\frac{T^{3}}{3}+\frac{2 t_{1}^{3}}{3}-t_{1}^{2} T\right)+\frac{a t_{1}^{2}}{2}\right] \\
+C(1-\gamma)\left[\theta\left(\frac{a t_{1}^{3}}{6}+\frac{b t_{1}^{4}}{8}\right)+\theta^{2}\left(\frac{a t_{1}^{5}}{40}+\frac{b t_{1}^{6}}{48}\right)\right]
\end{array}\right] \\
& +\frac{1}{T}\left(\pi\left[a\left(T-t_{1}\right)+\frac{b}{2}\left(T^{2}-t_{1}^{2}\right)\right]\right)=0
\end{aligned}
$$

Provided $\left(\frac{\partial^{2}\left(T C\left(t_{1}, T\right)\right)}{\partial t_{1}^{2}}\right)\left(\frac{\partial^{2}\left(T C\left(t_{1}, T\right)\right)}{\partial T^{2}}\right)-\left(\frac{\partial^{2}\left(T C\left(t_{1}, T\right)\right)}{\partial t_{1} \partial T}\right)^{2}>0$

$$
\frac{\partial^{2}\left(T C\left(t_{1}, T\right)\right)}{\partial t_{1}^{2}}=\frac{1}{T}\left[\begin{array}{l}
h\left[a+2 b t_{1}+\theta\left(a t_{1}^{2}+\frac{40 b t_{1}^{3}}{3}\right)+\theta^{2}\left(0.0111^{*} 30 a t_{1}^{4}+0.00952 * 42 b t_{1}^{5}\right)\right] \\
+\alpha\left[a t_{1}+\frac{3 b t_{1}^{2}}{2}+\theta\left(5 a t_{1}^{3}+\frac{3 b t_{1}^{4}}{4}\right)+\theta^{2}\left(\frac{42 a t_{1}^{5}}{336}+\frac{56 b t_{1}^{6}}{384}\right)\right]+ \\
\pi\left[b\left(2 t_{1}-T\right)+a\right] \\
+C(1-\gamma)\left[\theta\left(a t_{1}+\frac{3 b t_{1}^{2}}{2}\right)+\theta^{2}\left(\frac{a t_{1}^{3}}{2}+\frac{5 b t_{1}^{4}}{8}\right)\right]
\end{array}\right]
$$

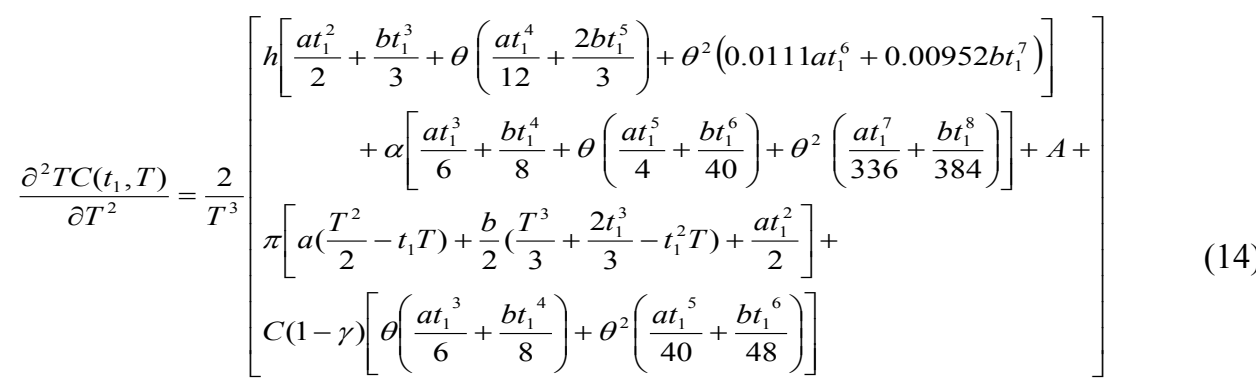

$$
+\pi\left[a\left(T-t_{1}\right)+\frac{b}{2}\left(T^{2}-t_{1}^{2}\right]+\pi(a+b T)\right.
$$


$\frac{\partial^{2} T C\left(t_{1}, T\right)}{\partial t_{1} \partial T}=-\frac{1}{T^{2}}\left[\begin{array}{l}h\left(a t_{1}+b t_{1}^{2}+\theta\left(\frac{a t_{1}^{3}}{3}+\frac{10}{3} b t_{1}^{5}\right)+\theta^{2}\left(0.0111 a t_{1}^{6}+0.00952 b t_{1}^{7}\right)\right) \\ +\alpha\left[\frac{a t_{1}^{2}}{2}+\frac{b t_{1}^{3}}{2}+\theta\left(\frac{5 a t_{1}^{4}}{4}+\frac{6 b t_{1}^{5}}{40}\right)+\theta^{2}\left(\frac{7 a t_{1}^{6}}{336}+\frac{8 b t_{1}^{7}}{384}\right)\right] \\ +\pi\left[-a T+\frac{b}{2}\left(2 t_{1}^{2}-2 t_{1} T\right)+a t_{1}\right] \\ +C(1-\gamma)\left[\theta\left(\frac{a t_{1}^{2}}{2}+\frac{b t_{1}^{3}}{2}\right)+\theta^{2}\left(\frac{a t_{1}^{4}}{8}+\frac{b t_{1}^{5}}{8}\right)\right]\end{array}\right]$

$+\pi\left(-a-b t_{1}\right)$

\section{Numerical Example}

By putting proper units of parametric values for

$\mathrm{A}=510 \mathrm{a}=200, \mathrm{~b}=20, \mathrm{C}=3$,

$\theta=0.01, \mathrm{~h}=1.5, \alpha=0.9, \pi=30$,

$\gamma=0.1$

Using MATHCAD Software, the optimal values the inventory system are

$\mathrm{t}_{1}=1.053, \mathrm{~T}=1.159, \mathrm{TC}=708.819$.

\section{Sensitivity Analysis}

We will study the effect of changes made in the values of the parameters A, a, b, $\alpha, C, \gamma$, and $\pi$ on the optimal cycle time, total cost and EOQ of these models. We have the following inferences can be made from Table-1:

Decrease in the parameters A and $\pi$ decreases the total optimal system cost. Similarly the increase in these parameters increases the total optimal cost. The effect of these parameters is more pronounced on the total cost of the system.

The effect of the parameters $a, b$ and $\alpha$ on the total optimal cost is similar but the rate of change is more in case of parameter a.

The total optimal cost of the system is not effected by the changes in the parameters $\mathrm{C}$ and $\gamma$. It may be conclude that the salvage value for deteriorated items is not effecting to the total cost.

Table-1

\begin{tabular}{|c|c|c|c|c|}
\hline Parameter & $\%$ change & $t_{1}$ & $\mathrm{~T}$ & $\mathrm{TC}$ \\
\hline \multirow[t]{4}{*}{$\mathrm{A}$} & -50 & -19.37 & -20.53 & -34.40 \\
\hline & -20 & -6.46 & -6.99 & -12.85 \\
\hline & +20 & 5.51 & 6.04 & 12.04 \\
\hline & +50 & 12.35 & 13.81 & 28.98 \\
\hline \multirow[t]{4}{*}{$\mathrm{a}$} & -50 & 11.87 & 15.01 & -17.98 \\
\hline & -20 & 4.37 & 5.18 & -6.75 \\
\hline & +20 & -3.89 & -4.40 & 6.31 \\
\hline & +50 & -9.02 & -10.01 & 15.10 \\
\hline \multirow[t]{4}{*}{$\mathrm{b}$} & -50 & 5.32 & 5.00 & -2.91 \\
\hline & -20 & 1.90 & 1.81 & -1.11 \\
\hline & +20 & -1.71 & -1.55 & 1.04 \\
\hline & +50 & -3.89 & -3.71 & 2.51 \\
\hline \multirow[t]{4}{*}{$\alpha$} & -50 & 2.85 & 2.42 & -2.41 \\
\hline & -20 & 1.14 & 0.95 & -0.95 \\
\hline & +20 & -1.04 & -0.86 & 0.92 \\
\hline & +50 & -2.56 & -2.07 & 2.27 \\
\hline \multirow[t]{4}{*}{$\mathrm{C}$} & -50 & 0.09 & 0.09 & -0.07 \\
\hline & -20 & 0.00 & 0.09 & -0.03 \\
\hline & +20 & 0.00 & 0.00 & 0.03 \\
\hline & +50 & -0.09 & 0.00 & 0.07 \\
\hline \multirow[t]{4}{*}{$\gamma$} & -50 & 0.00 & 0.00 & 0.01 \\
\hline & -20 & 0.00 & 0.00 & 0.00 \\
\hline & +20 & 0.00 & 0.00 & 0.01 \\
\hline & +50 & 0.00 & 0.09 & -0.01 \\
\hline \multirow[t]{4}{*}{$\pi$} & -50 & -2.28 & 6.30 & -4.24 \\
\hline & -20 & -0.57 & 1.64 & -1.12 \\
\hline & +20 & 0.38 & -1.04 & 0.77 \\
\hline & +50 & 0.85 & -2.16 & 1.57 \\
\hline
\end{tabular}




\section{Conclusions}

We have developed inventory management models for deteriorating items when the demand rate is assumed to be linear function of time. It is assumed that the deterioration rate is proportional to time. We have solved the model due to shortages. It is noted that the salvage value for deteriorated items is insignificant in the total optimal cost of the system.

\section{References}

[1] Ghrae P.M. and Schrader G.F., An Inventory model for exponentially deteriorating items, Journal of Industrial Engineering,14, $1963,238-243$

[2] Covert R.P and Philip G.C). An EOQ model for items with Weibull distribution deterioration, AIIE Transactions, 5, 1973, 323-326

[3] Aggarwal S.P, A note on an order-level inventory model for a system with constant rate of deterioration, Opsearch, 15, 1978, 84-187

[4] Dave U. and Patel L.K., (T, $\left.\mathrm{S}_{\mathrm{i}}\right)$ - policy inventory model for deteriorating items with time proportional demand. Journal of Operational Research Society,32, 1981, 137-142

[5] Deb M. and Chaudhuri K., A note on the heuristic for replenishment of trended inventories considering shortages. Journal of Operational Research Society,38, 1987, 459-463

[6] Hariga M, An EOQ model for deteriorating items with shortages and time-varying demand. Journal of Operational Research Society,46, 1995, 398-404

[7] Chakraborti T. and Chaudhuri K.S, An EOQ model for items with linear trend in demand and shortages in all cycles International Journal of Production Economics,49, 1996, 205-213

[8] Giri B.C and Chaudhuri K.S, Heuristic model for deteriorating items with shortages International Journal of System Science, $28,1997,153-159$

[9] Goyal S.K and Giri. B.C., Recent trends in modeling of deteriorating inventory European Journal of Operations research, Vol.134, 2001, pp.1-16.

[10] Mondal B., Bhunia A.K and Maiti M., An inventory system of ameliorating items for price dependent demand rate, Computers and Industrial Engineering,45(3),2003, 443-456

[11] You S.P., Inventory policy for products with price and time dependent demands, Journal of Operational Research Society,56, 2005, 870-873

[12] Ajanta Roy, An Inventory model for deteriorating items with price dependant demand and time-varying holding cost, AMOAdvanced modeling and optimization, volume 10, number 1, 2008

[13] Mishra V.K and Singh L.S , Deteriorating inventory model with time dependent demand and partial backlogging, Applied Mathematical sciences 4(72), 2010, 3611-3619

[14] Vinod Kumar Mishra, Inventory model for time dependent holding cost and deterioration with salvage value and shortages. The Journal of Mathematics and Computer Science Vol. 4 No.1 (2012) 37-47

[15] Vikas Sharma and Rekha Rani Chaudhuri, An inventory Model for deteriorating items with Weibull Deterioration with Time Dependent Demand and shortages, Research Journal of Management Sciences Vol.2(3), 2013, 28-30 